\title{
Genetic variants of interferon lambda-related genes and chronic kidney disease susceptibility in the Korean population
}

\author{
Jin Ho Kwak ${ }^{1}$, Jin Hyuk Paek², Gyeong Im Yu ${ }^{3}$, Seungyeup Han ${ }^{2}$, Woo Yeong Park², Yaerim Kim², \\ Dong Hoon Shin ${ }^{3}$, Kyubok Jin ${ }^{2}$ \\ ${ }^{1}$ Soksiwon Kwak \& Lee Clinic, Daegu, Republic of Korea \\ ${ }^{2}$ Division of Nephrology, Department of Internal Medicine, Keimyung University Dongsan Hospital, Keimyung University Kidney Institute, \\ Keimyung University School of Medicine, Daegu, Republic of Korea \\ ${ }^{3}$ Department of Preventive Medicine, Keimyung University School of Medicine, Daegu, Republic of Korea
}

Background: Chronic kidney disease (CKD) is a common condition leading to renal dysfunction and is closely related to increased cardiovascular and mortality risk. CKD is an important public health issue, and recent genetic studies have verified common CKD susceptibility variants. This research examines the interrelationship between candidate genes polymorphisms of interferon lambda (IFNL) induction, its signaling pathway, and CKD.

Methods: Seventy-five patients with advanced CKD and 312 healthy subjects (as controls) participated in this research. A replication set composed of 172 patients with advanced CKD and 365 controls was used for additional analysis. The genotype of single nucleotide polymorphisms (SNPs) was determined by the Axiom Genome-Wide Human Assay and SNaPshot assay.

Results: The SNP of IFNL3 was significantly associated with CKD in the codominant $(p=0.02)$ and dominant models $(p=0.02)$. In addition, the SNPs of IFNL2 were significantly associated with CKD in the dominant model $(p=0.03)$, and the SNP of interferon alpha receptor 2 (IFNAR2) was significantly associated with CKD in the log-additive model $(p=0.03)$. Concerning rs148543092, in the IFNL3 gene, a significant association was observed after pooling the original and replication sets.

Conclusion: These results indicate that SNPs in the IFNL induction and signal pathway may be associated with CKD risk in the Korean population. Finally, our results also show that the IFNL3 gene variant may be associated with CKD risk.

Keywords: Chronic renal insufficiency, DNA replication, Interferon type III, Single nucleotide polymorphism

\section{Introduction}

Chronic kidney disease (CKD) is a worldwide health prob- lem. The overall prevalence of CKD globally is estimated to be $11 \%$ to $13 \%[1,2]$, and CKD is a major risk factor for cardiovascular diseases and all-cause mortality [3]. Addi-

Received: March 30, 2021; Revised: December 22, 2021; Accepted: December 22, 2021

Correspondence: Kyubok Jin

Division of Nephrology, Department of Internal Medicine, Keimyung University Dongsan Hospital, Keimyung University Kidney Institute, Keimyung University School of Medicine, 1035 Dalgubeol-daero, Dalseo-gu, Daegu 42601, Republic of Korea. E-mail: mdjin922@gmail.com ORCID: https://orcid.org/0000-0002-7836-8863

Jin Ho Kwak and Jin Hyuk Paek contributed equally to this study as co-first authors.

Copyright (C) 2022 by The Korean Society of Nephrology

(a) This is an Open Access article distributed under the terms of the Creative Commons Attribution Non-Commercial and No Derivatives License (http:// creativecommons.org/licenses/by-nc-nd/4.0/) which permits unrestricted non-commercial use, distribution of the material without any modifications, and reproduction in any medium, provided the original works properly cited. 
tionally, CKD has become a socioeconomic and medical issue for global healthcare [4]. Therefore, it is paramount to identify individuals that are at risk for the development and progression of CKD.

A significant association between large numbers of genes, their polymorphisms, and kidney function was observed in genetic studies. Therefore, it can be concluded that a strong genetic component exists in CKD $[5,6]$. The pathogenesis of CKD is complex and dependent on a broad spectrum of diverse etiologies. A major pathophysiology of CKD is persistent, chronic inflammation [7]. In the active phase of inflammation, immune cells migrate to the injury site, resolve the damage, and initiate the healing process. However, persistent inflammation is problematic, as it can lead to tissue damage and fibrosis. In addition, chronic inflammation is associated with various diseases including CKD [8].

Interferon (IFN), a marker of inflammation, may play a role in CKD development. However, the role of IFN in CKD is not well understood. Type I IFNs are central mediators of antiviral immunity and kidney inflammation [9]. Although type III IFN, known as IFN lambda (IFNL), has several similarities in function with type I IFNs, little is known about the role of IFNL in CKD.

The IFNL signaling pathway is initiated as IFNL binds to the heterodimeric IFNL receptor. The IFNL receptor is composed of interleukin 28 receptor alpha (IL28RA) and interleukin 10 receptor beta (IL10RB) subunits, where the Janus kinase (JAK)-signal transducer and activator of the transcription (STAT) signaling cascade induces hundreds of IFN-stimulated genes (RIG-1-like receptor, toll-like receptor $[T L R]$, nuclear factor kappa-light-chain-enhancer of activated B cells, $I L$-28RA, $I L$-10RB, JAK1, tyrosine kinase 2, $S T A T$, IFN regulatory factor [IRF], IFN-stimulated response element, IFN-induced GTP-binding protein Mxl, and 2'-5'-oligoadenylate synthetase) [10].

This study explores the association between IFNL induction and signaling pathway candidate genes consisting of IFNL3, IFNL2, IFN alpha receptor 1 (IFNAR1), IFNAR2, TLR9, IL22, IL-1ORB, IRF7, JAK2, and STAT3 polymorphisms and CKD.

\section{Methods}

\section{Study subjects}

This study enrolled 90 patients with CKD who were distributed by the Keimyung Human Bio-Resource Bank in 2012. In addition, 312 control subjects who participated in health checkup programs from the health promotion center from July to October 2008 participated in this study. The control group was defined as those with no clinical evidence for kidney impairment, cancer, hypertension, diabetes mellitus, dyslipidemia, and cardiovascular diseases. Among the 90 patients with CKD, 75 (83.3\%) had an estimated glomerular filtration rate (eGFR) of less than $15 \mathrm{~mL} / \mathrm{min} / 1.73 \mathrm{~m}^{2}$. Since these patients could not represent the entire CKD group, we excluded patients with eGFR values above 15 $\mathrm{mL} / \mathrm{min} / 1.73 \mathrm{~m}^{2}$. A replication set consisting of $172 \mathrm{pa}-$ tients with advanced CKD and 365 controls was used for additional analysis.

Samples from 172 patients with advanced CKD were consecutively distributed by the Keimyung Human Bio-Resource Bank in 2018, and the controls were collected at the health promotion center of the Keimyung University Dongsan Medical Center (Daegu, Korea). Written informed consent was obtained from all the subjects. The approved protocol from the Institutional Review Board of the Keimyung University Dongsan Medical Center was used for this study (No. 2018-02-029).

\section{Clinical characteristics and biomedical measurement}

Participants' clinical characteristics, such as systolic blood pressure (SBP) and diastolic blood pressure (DBP) were measured. The body mass index (BMI) was calculated by weight divided by the square of the height $\left(\mathrm{kg} / \mathrm{m}^{2}\right)$.

Biochemical markers were measured using samples in the fasted state. The levels of fasting blood sugar (FBS), triglyceride, total cholesterol (TC), low-density lipoprotein (LDL) cholesterol, high-density lipoprotein (HDL) cholesterol, aspartate aminotransferase, alanine aminotransferase, albumin, blood urea nitrogen (BUN), creatinine, and uric acid were measured using an auto-analyzer (ADVIA2400 Chemistry System; Siemens Healthcare Diagnostics Inc., Tarrytown, NY, USA). eGFR was calculated using the simplified prediction equation derived from chronic 
kidney epidemiology collaboration (modification of diet in renal disease): $\mathrm{eGFR}=175 \times$ standardized $\mathrm{Scr}^{-1.154} \times$ age $^{-0.203}$ $\times 0.742$ [if female], where GFR is expressed as $\mathrm{mL} / \mathrm{min} / 1.73$ $\mathrm{m}^{2}$ of the body surface area and serum creatinine is expressed in $\mathrm{mg} / \mathrm{dL}$ [11]. CKD was defined as eGFR of $<60$ $\mathrm{mL} / \mathrm{min} / 1.73 \mathrm{~m}^{2}$ for 3 months or more.

Single nucleotide polymorphism selection and genotyping of the interferon lambda-related gene single nucleotide polymorphisms

Seventeen single nucleotide polymorphisms (IFNL3 gene 2SNPs, IFNL2 gene 2SNPs, IFNAR2 gene 2SNPs, TLR9 gene 2SNPs, IL-22 gene 2SNPs, IL10RB gene 2SNPs, IFNAR1 gene 1SNP, IRF7 gene 1SNP, JAK2 gene 1SNP, and STAT3 gene 1SNP) of the IFNL-related gene were selected based on database searches (http://ncbi.nlm.nih.gov/SNP). SNPs with $<0.05$ minor allele frequency, $<0.1$ heterozygosity, and unknown genotype frequencies in Asian populations were excluded. Human genomic DNA was extracted from peripheral blood samples using the Qiagen DNA Extraction Kit (Qiagen, Tokyo, Japan) and then stored at $20^{\circ} \mathrm{C}$. The SNPs of the IFNL3, IFNL2, IFNAR2, TLR9, IL-22, IL-10RB, IFNAR1, IRF7, JAK2, and STAT3 genes were genotyped by direct sequencing. The following primers for the 17 SNPs were used to amplify the genomic DNA (Table 1). Polymerase chain reaction (PCR) conditions included 32 cycles at $92^{\circ} \mathrm{C}$ for 30 seconds, $60^{\circ} \mathrm{C}$ for 50 seconds, and $70^{\circ} \mathrm{C}$ for 40 seconds. PCR products were identified on $1.5 \%$ agarose gel by electrophoresis. Furthermore, the PCR products were sequenced by the DNA analyzer (ABI Prism 3730XL; Applied Biosystems, Foster City, CA, USA) to analyze the genotypes of each SNP. Finally, the genotypes were determined using SeqManII software (DNASTAR Inc., Madison, WI, USA).

Genotyping of replication SNPs was screened using the single base primer extension assay with ABI PRISM SNaPShot Multiplex kit (ABI, Foster City, CA, USA) according to the manufacturer's protocol. Analysis was conducted using the Genemapper software (version 4.0; Applied Biosyste$\mathrm{ms})$.

\section{Statistical analysis}

IBM SPSS version 24 (IBM Corp., Armonk, NY, USA) and $\mathrm{R}$ version 3.2.2 (R Foundation for Statistical Computing, Vienna, Austria) were used for statistical analysis. The results were considered statistically significant when $\mathrm{p}<0.05$. Student $\mathrm{t}$ test was used for comparisons between the two groups among continuous variables. Additionally, con-

Table 1. Polymerase chain reaction primers of the SNPs in the interferon lambda-related genes

\begin{tabular}{|c|c|c|c|c|}
\hline Gene & SNP & Forward & Reverse & Product size \\
\hline IFNL3 & rs148543092 & 5'-GAGGATATGGTGCAGGGTGT-3' & 5'-СТСТАТССТССТСССССААС-3' & 201 bp \\
\hline IFNL3 & rs150748693 & 5'-GAAGGGTCAGACACACAGGT-3' & 5'-GAGCCCAGAACCCAGACAG-3' & $152 \mathrm{bp}$ \\
\hline IFNL2 & rs8103362 & 5'-СССТСАССТGСТСТТТСТСА-3' & 5'-GAGGATATGGTGCAGGGTGT-3' & 163 bp \\
\hline IFNL2 & rs59746524 & 5'-CCCACAGATCCAGCCTCAG-3' & 5'-TGTAGGGAGGAGGGGATGG-3' & $183 \mathrm{bp}$ \\
\hline IFNAR2 & rs2229207 & 5'-CAAAGATGCTTTTGAGCCAGA-3' & 5'-TTGCTTTCСАСТTAАСTCСTGA-3' & $208 \mathrm{bp}$ \\
\hline IFNAR2 & rs1051393 & 5'-TTGATCACCTAATGTTGATTTCAGA-3' & 5'-AGGGTGGTACTGGGTCCTCT-3' & $234 \mathrm{bp}$ \\
\hline TLR9 & rs187084 & 5'-GCTGGGTGTACATAATTCAGCA-3' & 5'-GAGCTCCTTTGCCTGGTCTA-3' & $220 \mathrm{bp}$ \\
\hline TLR9 & rs5743836 & 5'-GGGGTGGGAGGTTTGTAAGA-3' & 5'-CTGTTCCCCTGAGTGCTCT-3' & $217 \mathrm{bp}$ \\
\hline IL-22 & rs2227513 & 5'-СТTCTАССТTССССGTCACA-3' & 5'-GGTCCCCATAAGGAAAGAGC-3' & $218 \mathrm{bp}$ \\
\hline IL-22 & rs2227484 & 5'-GATATATTTACTTCTGCCTTAATTG-3' & 5'-GGACCCATGTCCTATATCCTC-3' & $220 \mathrm{bp}$ \\
\hline IL-22 & rs2227485 & 5'-TCCGTGACCAAAATGCTTACTC-3' & 5'-ACGTCACTATTAGAGCCCGG-3' & $165 \mathrm{bp}$ \\
\hline IL-10RB & rs8178562 & 5'-TCAGAAGTTGGCCACTGAGA-3' & 5'-CGCCATCATGCCTAGCTAAT-3' & $231 \mathrm{bp}$ \\
\hline IL-10RB & rs2834167 & 5'-СТСТСТАССТСTTCCGCCGTCTACA-3' & 5'-GGTCCCCATAAGGAAAGAGC-3' & $223 \mathrm{bp}$ \\
\hline IFNAR1 & Affx-52347487 & 5'-GAGAAACTGGGGGTCCCCCA-3' & 5'-GCTCCGGTGGTAAGGTGC-3' & $104 \mathrm{bp}$ \\
\hline IRF7 & Affx-52325648 & 5'-GCTACACGGAGGAACTGCTG-3' & 5'-GCCTCACTGACCTTGGAAGA-3' & $218 \mathrm{bp}$ \\
\hline JAK2 & rs77375493 & 5'-AGCAAGTATGATGAGCAAGCT-3' & 5'-ACCTAGCTGTGATCCTGAAACT-3' & $163 \mathrm{bp}$ \\
\hline STAT3 & rs113994139 & 5'-TTCCTTCCСАTGTCCTGTGA-3' & 5'-CTGGCCGACAATACTTTCCG-3' & 203 bp \\
\hline
\end{tabular}

SNP, single nucleotide polymorphism. 
tinuous variables were presented as the mean \pm standard deviation. The chi-square test was used for comparison between the two groups among the categorical variables. Categorical variables were presented as the frequency, percentage, and odds ratio (OR) and $95 \%$ confidence intervals (CIs) were calculated. To estimate the Hardy-Weinberg equilibrium (HWE), logistic regression analysis for the genetic data was used for SNPStats (http://bioinfo.iconcologia.net/index.php) and IBM SPSS version 24. Allele frequency comparison between the two groups was used for the chi-square test. The associations between SNPs and CKD were estimated by computing the OR and their $95 \%$ CI with logistic regression analyses adjusted for age and sex as covariates. In the CKD group, multivariate logistic regression analysis of the gene data and clinical variables was used with R version 3.2.2. Age, sex, BMI, hypertension, diabetes mellitus, and dyslipidemia were adjusted as covariates in multivariate logistic regression.

\section{Results}

Demographic and clinical characteristics of the participants

The demographic characteristics and clinical parameters of the study subjects are summarized in Table 2 . The original set consisted of 312 control subjects included 157 males and 155 females with a mean age of $46.7 \pm 10.3$ years. The CKD group was composed of 75 adults and involved 36 males and 39 females with a mean age of $50.2 \pm 12.1$ years. In the replication set, 365 control subjects included 177 males and 188 females with a mean age of $50.6 \pm 13.8$ years. The CKD group was composed of 172 adults and included 92 males and 80 females with a mean age of 59.2 \pm 15.1 years. In the original and replication sets, the sex distribution of the subjects was not significantly different in the two groups. Additionally, in the original and replication sets, BMI, SBP, DBP, BUN, creatinine, uric acid, FBS, and triglyceride levels in the CKD group were significantly higher compared to the control group. Conversely, eGFR, total protein, albumin, TC, HDL cholesterol, and LDL cholesterol levels in the CKD group were significantly lower compared to the control group. In the control and CKD groups, the genotype distribution of the 17 polymorphic SNPs was in the HWE.
Genotype and allele frequencies of the IFNL3, IFNL2, IFNAR2, TLR9, IL-1ORB, IL-22, IFNAR, IRF7, JAK2, and STAT3 genes' single nucleotide polymorphisms

The SNPs of IFNL3, rs148543092 (T > C), were significantly associated with CKD in the codominant and dominant models ( $\mathrm{T} / \mathrm{T}$ vs. $\mathrm{T} / \mathrm{C}$ and $\mathrm{T} / \mathrm{T}$ vs. $\mathrm{T} / \mathrm{C}+\mathrm{C} / \mathrm{C}, \mathrm{p}=0.02, \mathrm{OR}=$ $2.61,95 \% \mathrm{CI}=1.28-5.80)$. The SNPs of IFNL2, rs8103362 $(A>G)$, were significantly associated with CKD in the codominant, dominant, and log-additive models (A/A vs. A/ $\mathrm{G}, \mathrm{p}=0.06, \mathrm{OR}=2.61,95 \% \mathrm{CI}=1.18-5.80 ; \mathrm{A} / \mathrm{A}$ vs. $\mathrm{A} / \mathrm{G}+\mathrm{G} /$ $\mathrm{G}, \mathrm{p}=0.03, \mathrm{OR}=2.45,95 \% \mathrm{CI}=1.11-5.40 ; \mathrm{A} / \mathrm{A}$ vs. $\mathrm{A} / \mathrm{G}$ vs. $\mathrm{G} / \mathrm{G}, \mathrm{p}=0.05, \mathrm{OR}=2.17 ; 95 \% \mathrm{CI}=1.02-4.63$, respectively). The SNP of IFNAR2, rs1051393 ( $\mathrm{G}>\mathrm{T}$ ), was significantly associated with CKD in the codominant and log-additive models ( $\mathrm{G} / \mathrm{G}$ vs. $\mathrm{T} / \mathrm{T}, \mathrm{p}=0.05$, $\mathrm{OR}=2.10,95 \% \mathrm{CI}=1.00-4.40$; $\mathrm{G} / \mathrm{G}$ vs. $\mathrm{G} / \mathrm{T}$ vs. $\mathrm{T} / \mathrm{T}, \mathrm{p}=0.047, \mathrm{OR}=1.42,95 \% \mathrm{CI}=1.01-2.00$, respectively) (Table 3$)$. There was no significant difference in the genotype and allele frequencies between the control and CKD group in the SNP of TLR9, rs187084 (T > C), SNP of $I L-22$, rs2227484 (G > A), IL-10RB gene polymorphisms (rs8178562 G > A, rs 2834167 A > G), and IRF7 gene polymorphism (Affix-52325648 T/del). Finally, there were no polymorphisms, but only major allele homozygotes in IFNAR1 (Affix-52347487), JAK2 (rs77375493), and STAT3 (rs113994139) (data not shown). Genotype and allele frequencies of the IFNL-related genotype in the replication set are shown in Supplementary Table 1 (available online).

\section{Replication of the IFNL3, IFNL2, and IFNAR2 genes' single nucleotide polymorphisms}

Comparing genotypic frequencies between cases and controls for all SNPs analyzed achieved a significant nominal value in three polymorphisms located in three genetic regions. We attempted to replicate associations involving IFNL3, IFNL2, and IFNAR2 using a second sample set (Table 4).

No significant associations involving IFNL2 and $I F$ NAR2 were observed in the replication set. Regarding rs148543092, in the IFNL3 gene, a significant association was observed after pooling the original and replication sets $(\mathrm{p}=0.02, \mathrm{OR}=2.50,95 \% \mathrm{CI}=1.14-5.47 ; \mathrm{p}<0.001, \mathrm{OR}=0.92$, 95\% CI, 0.89-0.95) (Table 4). 
Table 2. Demographic characteristics and clinical parameters for the study population

\begin{tabular}{|c|c|c|c|c|c|c|}
\hline & \multicolumn{3}{|c|}{ Original set } & \multicolumn{3}{|c|}{ Replication set } \\
\hline & Control & CKD & $p$-value & Control & CKD & p-value \\
\hline No. of patients & 312 & 75 & NA & 365 & 172 & NA \\
\hline Age (yr) & $46.7 \pm 10.3$ & $50.2 \pm 12.1$ & $0.01^{a}$ & $50.6 \pm 13.8$ & $59.2 \pm 15.1$ & $<0.001^{\mathrm{a}}$ \\
\hline Male & $47.2 \pm 10.5$ & $51.8 \pm 9.6$ & NA & $50.3 \pm 13.6$ & $60.5 \pm 14.1$ & NA \\
\hline Female & $46.2 \pm 10.1$ & $48.9 \pm 13.9$ & NA & $50.9 \pm 14.1$ & $58.8 \pm 16.1$ & NA \\
\hline \multicolumn{7}{|l|}{ Sex } \\
\hline Male/female & $157(50.3) / 155(49.7)$ & $36(48.0) / 39(52.0)$ & $0.79^{b}$ & $177(48.5) / 188(51.5)$ & $92(53.5) / 80(46.5)$ & $0.16^{b}$ \\
\hline \multicolumn{7}{|l|}{ Etiology } \\
\hline Diabetes mellitus & NA & $24(32.0)$ & NA & NA & $70(40.7)$ & NA \\
\hline Hypertension & NA & $4(5.3)$ & NA & NA & $22(12.8)$ & NA \\
\hline Chronic glomerulonephritis & NA & $46(61.3)$ & NA & NA & $74(43.0)$ & NA \\
\hline Others & NA & $1(1.3)$ & NA & NA & $6(3.5)$ & NA \\
\hline Renal replacement therapy & NA & $69(92.0)$ & NA & NA & $151(87.8)$ & NA \\
\hline Left ventricular hypertrophy & NA & $16(21.3)$ & NA & NA & $34(19.5)$ & NA \\
\hline Body mass index $\left(\mathrm{kg} / \mathrm{m}^{2}\right)$ & $22.5 \pm 2.6$ & $23.8 \pm 3.6$ & $0.003^{\mathrm{a}}$ & $22.5 \pm 2.9$ & $23.6 \pm 4.0$ & $0.003^{\mathrm{a}}$ \\
\hline $\begin{array}{l}\text { Systolic blood pressure } \\
(\mathrm{mmHg})\end{array}$ & $109.0 \pm 7.2$ & $143.7 \pm 21.7$ & $<0.001^{\mathrm{a}}$ & $109.0 \pm 9.0$ & $138.6 \pm 22.7$ & $<0.001^{\mathrm{a}}$ \\
\hline $\begin{array}{l}\text { Diastolic blood pressure } \\
(\mathrm{mmHg})\end{array}$ & $68.7 \pm 5.9$ & $84.7 \pm 12.9$ & $<0.001^{a}$ & $68.6 \pm 6.1$ & $79.1 \pm 12.6$ & $<0.001^{a}$ \\
\hline Blood urea nitrogen $(\mathrm{mg} / \mathrm{dL})$ & $13.9 \pm 3.6$ & $72.8 \pm 26.4$ & $<0.001^{\mathrm{a}}$ & $14.3 \pm 3.8$ & $78.1 \pm 29.1$ & $<0.001^{a}$ \\
\hline Creatinine (mg/dL) & $0.9 \pm 0.2$ & $8.4 \pm 3.0$ & $<0.001^{\mathrm{a}}$ & $0.9 \pm 0.2$ & $7.9 \pm 3.1$ & $<0.001^{\mathrm{a}}$ \\
\hline $\operatorname{eGFR}\left(\mathrm{mL} / \mathrm{min} / 1.73 \mathrm{~m}^{2}\right)$ & $76.7 \pm 11.4$ & $6.8 \pm 2.7$ & $<0.001^{a}$ & $75.9 \pm 11.1$ & $7.2 \pm 2.7$ & $<0.001^{a}$ \\
\hline Uric acid (mg/dL) & $4.6 \pm 1.3$ & $8.5 \pm 2.6$ & $<0.001^{\mathrm{a}}$ & $4.6 \pm 1.3$ & $8.7 \pm 2.6$ & $<0.001^{a}$ \\
\hline Fasting blood sugar (mg/dL) & $85.8 \pm 6.6$ & $128.5 \pm 63.6$ & $<0.001^{a}$ & $86.6 \pm 8.0$ & $125.7 \pm 80.1$ & $<0.001^{\mathrm{a}}$ \\
\hline Total protein $(\mathrm{g} / \mathrm{dL})$ & $7.4 \pm 0.4$ & $6.3 \pm 0.8$ & $<0.001^{a}$ & $7.4 \pm 0.4$ & $6.2 \pm 0.8$ & $<0.001^{\mathrm{a}}$ \\
\hline Albumin (g/dL) & $4.4 \pm 0.2$ & $3.5 \pm 0.5$ & $<0.001^{a}$ & $4.4 \pm 0.2$ & $3.5 \pm 0.6$ & $<0.001^{\mathrm{a}}$ \\
\hline AST (IU/L) & $21.5 \pm 5.2$ & $18.6 \pm 15.6$ & $0.11^{a}$ & $22.0 \pm 5.5$ & $20.3 \pm 34.8$ & $0.52^{a}$ \\
\hline ALT (IU/L) & $17.6 \pm 6.7$ & $18.9 \pm 23.7$ & $0.62^{a}$ & $17.6 \pm 6.7$ & $18.1 \pm 29.6$ & $0.81^{a}$ \\
\hline Total cholesterol (mg/dL) & $186.3 \pm 25.3$ & $164.2 \pm 45.4$ & $<0.001^{\mathrm{a}}$ & $186.0 \pm 26.1$ & $158.7 \pm 47.2$ & $<0.001^{\mathrm{a}}$ \\
\hline Triglyceride (mg/dL) & $88.2 \pm 35.8$ & $123.1 \pm 79.7$ & $0.004^{a}$ & $91.8 \pm 37.9$ & $159.0 \pm 127.7$ & $<0.001^{a}$ \\
\hline HDL cholesterol (mg/dL) & $55.4 \pm 11.1$ & $42.1 \pm 15.2$ & $<0.001^{\mathrm{a}}$ & $55.2 \pm 11.1$ & $44.5 \pm 23.2$ & $0.001^{\mathrm{a}}$ \\
\hline LDL cholesterol (mg/dL) & $113.0 \pm 25.0$ & $99.4 \pm 37.9$ & $0.02^{a}$ & $113.3 \pm 24.9$ & $95.8 \pm 41.4$ & $0.006^{\mathrm{a}}$ \\
\hline
\end{tabular}

Data are expressed as number only, mean \pm standard deviation or number (\%).

ALT, alanine aminotransferase; AST, aspartate aminotransferase; CKD, chronic kidney disease; eGFR, estimated glomerular filtration rate; HDL, high-density lipoprotein; LDL, low-density lipoprotein; NA, not applicable.

The $p$-values were analyzed using ${ }^{a}$ the $t$ test or ${ }^{b}$ the chi-square test.

\section{Association of IFNL3 single nucleotide polymorphism with clinical characteristics}

After adjustments for age, sex, BMI, hypertension, diabetes mellitus, and dyslipidemia as covariates, we examined whether the genotype distribution of IFNL3 gene polymorphism, rs148543092, is associated with clinical characteristics (creatinine, eGFR, uric acid, total protein, and albumin) in the original and replication sets of the CKD group. In addition, in the original and replication sets, cre- atinine, eGFR, uric acid, total protein, and albumin levels exhibited no significant difference in the genotype distribution (Table 5).

\section{Discussion}

This study examines the association between the polymorphisms of IFNL3 (rs148543092 T > C), IFNL2 (rs8103362 A $>\mathrm{G})$, IFNAR2 (rs1051393 G > T), TLR9 (rs187084 T > C), IL22 (rs2227513 T > C), and CKD development in patients 
Table 3. Distribution of frequencies of the interferon lambda-related genotype in controls and chronic kidney disease patients in the model of inheritance

\begin{tabular}{|c|c|c|c|c|c|c|c|c|c|c|}
\hline \multirow{3}{*}{ Gene } & \multirow{3}{*}{ SNP number } & \multirow{3}{*}{ Function } & \multicolumn{8}{|c|}{ Model of inheritance } \\
\hline & & & \multicolumn{2}{|c|}{$\begin{array}{c}\text { Codominant genetic } \\
\text { model }\end{array}$} & \multicolumn{2}{|c|}{$\begin{array}{l}\text { Dominant genetic } \\
\text { model }\end{array}$} & \multicolumn{2}{|c|}{$\begin{array}{l}\text { Recessive genetic } \\
\text { model }\end{array}$} & \multicolumn{2}{|c|}{$\begin{array}{l}\text { Log-additive genetic } \\
\text { model }\end{array}$} \\
\hline & & & OR (95\% Cl) & p-value & OR (95\% Cl) & $p$-value & OR $(95 \% \mathrm{Cl})$ & p-value & OR (95\% Cl) & p-value \\
\hline \multirow[t]{2}{*}{ IFNL3 } & rs148543092 & Missense & $\begin{array}{c}2.61 \\
(1.28-5.80)\end{array}$ & 0.02 & $\begin{array}{c}2.61 \\
(1.28-5.80)\end{array}$ & 0.02 & NA & NA & NA & NA \\
\hline & Thr108Ala & & NA & NA & NA & NA & NA & NA & NA & NA \\
\hline IFNL2 & Thr112Ala & & NA & NA & NA & NA & NA & NA & NA & NA \\
\hline \multirow[t]{2}{*}{ IFNAR2 } & rs1051393 & Missense & $\begin{array}{c}1.53 \\
(0.82-2.88)\end{array}$ & 0.18 & $\begin{array}{c}1.68 \\
(0.92-3.06)\end{array}$ & 0.08 & $\begin{array}{c}1.59 \\
(0.87-2.90)\end{array}$ & 0.14 & $\begin{array}{c}1.42 \\
(1.01-2.00)\end{array}$ & 0.047 \\
\hline & Phe10lle & & $\begin{array}{c}2.10 \\
(1.00-4.40)\end{array}$ & 0.05 & NA & NA & NA & NA & NA & NA \\
\hline \multirow[t]{2}{*}{ IL-22 } & rs2227513 & NearGene-5' & $\begin{array}{c}1.97 \\
(0.32-12.28)\end{array}$ & 0.48 & $\begin{array}{c}1.97 \\
(0.32-12.28)\end{array}$ & 0.48 & NA & NA & NA & NA \\
\hline & $\mathrm{T}-111 \mathrm{C}$ & & NA & NA & NA & NA & NA & NA & NA & NA \\
\hline
\end{tabular}

$\mathrm{Cl}$, confidence interval; OR, odds ratio; SNP, single nucleotide polymorphism; NA, not applicable.

Table 4. Distribution of the frequencies of the IFNL3 genotype

\begin{tabular}{|c|c|c|c|c|}
\hline \multirow{2}{*}{ IFNL3 rs148543092 genotype } & \multicolumn{2}{|c|}{ Original set ${ }^{a}$} & \multicolumn{2}{|c|}{ Replication set ${ }^{\mathrm{b}}$} \\
\hline & $\operatorname{CKD}(n=75)$ & Control $(n=312)$ & $\operatorname{CKD}(n=172)$ & Control $(n=365)$ \\
\hline TT & $64(85.3)$ & 291 (93.6) & $172(100)$ & 338 (92.9) \\
\hline $\mathrm{CC}$ & $0(0.0)$ & $0(0)$ & $0(0)$ & $0(0)$ \\
\hline
\end{tabular}

Data are expressed as number (\%).

TT vs. TC + CC.

CKD, chronic kidney disease.

The $p$-values were analyzed using the chi-square test: ${ }^{a} p=0.02$, odds ratio (OR), 2.50 (95\% confidence interval [Cl], 1.14-5.47); ${ }^{b} p<0.001,0 R$, 0.92 (95\% Cl, 0.89-0.95).

Table 5. Association of IFNL3 SNP with the clinical characteristics

\begin{tabular}{|c|c|c|c|c|c|c|c|}
\hline \multirow[b]{2}{*}{ SNP } & \multirow[b]{2}{*}{ Parameter } & \multicolumn{2}{|c|}{ Genotype } & \multirow[b]{2}{*}{$p$-value ${ }^{a}$} & \multicolumn{2}{|c|}{ Genotype } & \multirow[b]{2}{*}{$p$-value ${ }^{b}$} \\
\hline & & $\begin{array}{c}T / T \\
(n=64)\end{array}$ & $\begin{array}{c}T / C+C / C \\
(n=11)\end{array}$ & & $\begin{array}{c}\mathrm{T} / \mathrm{T} \\
(\mathrm{n}=172)\end{array}$ & $\begin{array}{c}T / C+C / C \\
(n=0)\end{array}$ & \\
\hline \multirow[t]{4}{*}{ rs148543092 } & Creatinine $(\mathrm{mg} / \mathrm{dL})$ & $8.32 \pm 2.95$ & $8.78 \pm 3.64$ & 0.64 & $7.86 \pm 3.14$ & NA & NA \\
\hline & Uric acid (mg/dL) & $8.53 \pm 2.76$ & $8.55 \pm 1.86$ & 0.98 & $8.69 \pm 2.62$ & NA & NA \\
\hline & Total protein $(\mathrm{g} / \mathrm{dL})$ & $6.36 \pm 0.71$ & $5.90 \pm 1.09$ & 0.21 & $6.25 \pm 0.78$ & NA & NA \\
\hline & Albumin (g/dL) & $3.53 \pm 0.45$ & $3.35 \pm 0.67$ & 0.25 & $3.53 \pm 0.56$ & NA & NA \\
\hline
\end{tabular}

Data are expressed as mean \pm standard deviation.

eGFR, estimated glomerular filtration rate; SNP, single nucleotide polymorphisms; NA, not applicable.

The $p$-values were analyzed using the $t$ test: ${ }^{a}$ original set and ${ }^{b}$ replication set. 
with advanced CKD. The SNPs of IFNAR2 (rs1051393), IFNL2 (rs8103362), and IFNL3 (rs148543092) were significantly associated with CKD. Among them, the frequency of rs 148543092 in IFNL3 was significantly higher in CKD than the control group in the original and replication sets.

Persistent, low-grade inflammation is considered an essential component of CKD, playing an important role in its pathophysiology [12]. Patients with CKD exhibit elevated cytokine levels and dysregulated cytokine metabolism, leading to increased circulating acute-phase proteins [13]. In addition, IFN, an inflammatory cytokine, may play a regulatory role in the development and progression of CKD. However, the role of IFN in CKD is not well understood, especially in IFNL.

Additionally, type III IFN (IFNL) is associated with a cytokine family that has several similarities in functions with type I IFNs (either IFN- $\alpha$, IFN- $\beta$, or IFN- $\alpha / \beta$ ). The four IFNL proteins (IFNL1, IFNL2, IFNL3, and IFNL4) and 17 IFN- $\alpha / \beta$ proteins (13 IFN- $\alpha$ subtypes, IFN- $\beta$, IFN- $\omega$, IFN- $\varepsilon$, and IFN- $\kappa$ ) are encoded by genes in humans [14]. Located in human chromosome 19, genes encoding IFNL have a similar gene structure with the 5-exon gene of the IL-10 cytokine family [15]. IFNL has several biological features, which begin with IFNL effectiveness. The efficacy of IFNL is most pronounced in epithelial cells where it explicitly strengthens the immune systems that protect the surface of the upper skin that is exposed to general and pathogenic microorganisms [16]. IFNL is involved in inflammation, one of the main pathophysiologies of CKD, and is expected to affect CKD development. This is the first study to identify the association between IFNL and CKD to the best of our knowledge.

IFNL has emerged as a new immune control cytokine with a particular function controlling damage to maintain an immune balance and limit immunology. In addition, IFN $\lambda$ limits inflammation to prevent damage to the host by chronic illnesses including asthma, auto-immune diseases, and colitis [17]. The genetic association of IFNL gene polymorphisms among humans expands to various illnesses such as allergies, nonalcoholic fatty liver disease, and several other viral diseases caused by human immunodeficiency virus and hepatitis $C$ virus infections [18]. The difference in expression levels by the IFNL3 genotype was shown in numerous studies. For example, recent research outcomes verified this result in ex/in vivo condi- tions. These results demonstrate that differences in IFNL3 expression levels by the alleles at the three functional SNPs (rs28416813, rs4803217, and rs59702201) may play a role in the disease [19-21]. Furthermore, a recent study revealed that genetic variants of $I F N L 3 / 4$ play an essential role in developing lupus nephritis and systemic lupus erythematosus in the Taiwanese population [22]. However, little is known about the association between IFNL and CKD. In the present study, we demonstrate that the SNP of IFNL3 (rs148543092) is significantly associated with CKD development in patients with advanced CKD. Furthermore, these results are consistent with the entire CKD cohort (Supplementary Table 2, available online).

Additionally, several researchers have reported SNPs of IFNAR2 in hepatitis B virus (HBV) infections. Specifically, IFNAR2 polymorphisms may be involved in chronic HBV infection susceptibility among the Thai population [23]. It may also be involved when determining IFN response and predictive markers of HBV infections among the Chinese Han population [24]. Ma et al. [25] reported that the polymorphism of IFNAR2 (rs1051393 G > T) is a missense changing from phenylalanine to valine. This SNP may be important in the risk of HBV infection by influencing the expression of IFNAR2 protein on the cell's surface, resulting in an antiviral response and damaged signal transduction. Our result also suggests that IFNAR2 polymorphisms (rs1051393 G > T) are associated with CKD. This research found that the T allele of IFNAR2 (rs1051393 G > T) was higher in the CKD group compared with the control. The interrelationship of this SNP may be a codominant effect shown by the inheritance analysis model (major allele homozygotes vs. minor allele homozygotes). Therefore, this study indicates that the mechanism underlying the association between IFNAR2 SNP (rs1051393 G > T) and CKD may control IFNAR2 expression, which affects the type I IFN effect.

CKD and end-stage kidney disease are featured by increased proinflammatory cytokine levels and inflammatory labeling. Cytokines may control the risk of developing kidney disease [13] and induce resident cells to proliferate and influence metalloproteinases, bioactive lipids, the expression of adhesion receptors, reactive oxygen/nitrogen species, procoagulant activity of the endothelium, and aberrant matrix metabolism. In addition, these molecules may be the action mediators of the renin-angiotensin sys- 
tem and hemodynamic factors [26-33]. IL-10, an anti-inflammatory cytokine with numerous functions, is primarily secreted by monocytes and lymphocytes. IL-22, an IL-10related cytokine, activates the upward adjustment of the acute-phase reactor. It also guides JAK/STAT activation in several cell lines, including hepatomas, intestinal epithelial cells, and mesangial cells [34]. Meta-analysis outcomes have shown that the $I L$-22 gene rs1179251 polymorphism (but not rs2227485 polymorphism) may be a cancer risk factor [35]. The rs2227485 SNP of $I L-22$ may have a connection with the risk and multifocality of primary thyroid cancers according to Eun et al. [36]. However, this research did not show that the association between polymorphisms (rs2227513 T > C; rs2227485 G > A) of the $I L-22$ gene and CKD development exhibited an association with rs2227484 polymorphisms.

Furthermore, the second sample set was used to analyze replicate associations involving IFNL3, IFNL2, IFNAR2, TLR9, and IL22. No significant associations involving IFNL2, IFNAR2, TLR9, and IL22 were observed in the replication set. Whereas concerning rs148543092, in the IFNL3 gene, a significant association was observed after pooling the original and replication sets. These results suggest that IFNL3 polymorphisms are associated with CKD. However, there were no significant differences between the clinical characteristics and genotypes of IFNL3.

There are several limitations to this study. First, this study was a single-center study and the sample size was relatively small. However, we performed a genetic analysis of the association between IFNL induction and signal pathway genes, such as IFNL3, IFNL2, IFNAR2, TLR9, IL-22, and $I L-10 R B$ and CKD, for the first time. Second, we analyzed advanced CKD rather than entire CKD patients due to the characteristics of our study cohort. However, even when entire CKD patients were analyzed, the same SNP of IFNL3 was associated with CKD. Third, homozygous genotypes were observed in CKD patients in the replication set. However, the heterozygous genotypes were observed in the original set which indicated that CKD had IFNL3 polymorphisms.

In conclusion, the outcome of this study indicates the possibility of an association between IFNL induction polymorphisms and signal pathway genes with CKD in the Korean population. Furthermore, our results indicate that the IFNL3 gene variant may be associated with CKD risk.
Therefore, early interventions in patients with high-risk genotypes may delay CKD progression. However, further large-scale prospective studies are necessary to establish the role of IFNL in CKD.

\section{Conflicts of interest}

All authors have no conflicts of interest to declare.

\section{Funding}

The present research has been conducted by the Research Grant of Kidney Institute, Keimyung University in 2017.

\section{Authors' contributions}

\section{Conceptualization: JHK, DHS, KJ}

Data curation: JHK, JHP

Formal analysis: JHK, JHP, GIY

Funding acquisition: $\mathrm{KJ}$

Investigation: GIY

Writing-original draft: JHK, DHS, GIY, SH, WYP, YK

Writing-review \& editing: JHP, KJ

All authors read and approved the final manuscript.

\section{ORCID}

Jin Ho Kwak, https://orcid.org/0000-0002-5758-812X Jin Hyuk Paek, https://orcid.org/0000-0001-8875-1260 Gyeong Im Yu, https://orcid.org/0000-0003-1494-3977 Seungyeup Han, https://orcid.org/0000-0002-7561-6534 Woo Yeong Park, https://orcid.org/0000-0003-2662-2898 Yaerim Kim, https://orcid.org/0000-0003-1596-1528 Dong Hoon Shin, https://orcid.org/0000-0002-3623-7013 Kyubok Jin, https://orcid.org/0000-0002-7836-8863

\section{References}

1. Levin A, Tonelli M, Bonventre J, et al. Global kidney health 2017 and beyond: a roadmap for closing gaps in care, research, and policy. Lancet 2017;390:1888-1917.

2. Hill NR, Fatoba ST, Oke JL, et al. Global prevalence of chronic kidney disease: a systematic review and meta-analysis. PLoS One 2016;11:e0158765.

3. Gansevoort RT, Correa-Rotter R, Hemmelgarn BR, et al. Chronic 
kidney disease and cardiovascular risk: epidemiology, mechanisms, and prevention. Lancet 2013;382:339-352.

4. Zhang QL, Rothenbacher D. Prevalence of chronic kidney disease in population-based studies: systematic review. BMC Public Health 2008;8:117.

5. O'Seaghdha CM, Fox CS. Genetics of chronic kidney disease. Nephron Clin Pract 2011;118:c55-c63.

6. Köttgen A, Glazer NL, Dehghan A, et al. Multiple loci associated with indices of renal function and chronic kidney disease. Nat Genet 2009;41:712-717.

7. Mihai S, Codrici E, Popescu ID, et al. Inflammation-related mechanisms in chronic kidney disease prediction, progression, and outcome. J Immunol Res 2018;2018:2180373.

8. Germolec DR, Shipkowski KA, Frawley RP, Evans E. Markers of inflammation. Methods Mol Biol 2018;1803:57-79.

9. Anders HJ, Lichtnekert J, Allam R. Interferon-alpha and -beta in kidney inflammation. Kidney Int 2010;77:848-854.

10. Syedbasha M, Egli A. Interferon lambda: modulating immunity in infectious diseases. Front Immunol 2017;8:119.

11. Stevens LA, Stoycheff N. Standardization of serum creatinine and estimated GFR in the Kidney Early Evaluation Program (KEEP). Am J Kidney Dis 2008;51(4 Suppl 2):S77-S82.

12. Akchurin OM, Kaskel F. Update on inflammation in chronic kidney disease. Blood Purif 2015;39:84-92.

13. Rao M, Wong C, Kanetsky P, et al. Cytokine gene polymorphism and progression of renal and cardiovascular diseases. Kidney Int 2007;72:549-556.

14. Lazear HM, Nice TJ, Diamond MS. Interferon- $\lambda$ : immune functions at barrier surfaces and beyond. Immunity 2015;43:15-28.

15. Sabat R. IL-10 family of cytokines. Cytokine Growth Factor Rev 2010;21:315-324.

16. Stanifer ML, Guo C, Doldan P, Boulant S. Importance of type I and III interferons at respiratory and intestinal barrier surfaces. Front Immunol 2020;11:608645.

17. Andreakos E, Zanoni I, Galani IE. Lambda interferons come to light: dual function cytokines mediating antiviral immunity and damage control. Curr Opin Immunol 2019;56:67-75.

18. Chinnaswamy S. Gene-disease association with human IFNL locus polymorphisms extends beyond hepatitis $\mathrm{C}$ virus infections. Genes Immun 2016;17:265-275.

19. Chinnaswamy S. Genetic variants at the IFNL3 locus and their association with hepatitis $\mathrm{C}$ virus infections reveal novel insights into host-virus interactions. J Interferon Cytokine Res 2014;34:479-497.

20. Noureddin M, Rotman Y, Zhang F, et al. Hepatic expression lev- els of interferons and interferon-stimulated genes in patients with chronic hepatitis C: a phenotype-genotype correlation study. Genes Immun 2015;16:321-329.

21. Kurbanov F, Kim Y, Latanich R, et al. IFNL3 genotype is associated with differential induction of IFNL3 in primary human hepatocytes. Antivir Ther 2015;20:805-814.

22. Chen JY, Wang CM, Chen TD, et al. Interferon- $\lambda 3 / 4$ genetic variants and interferon- $\lambda 3$ serum levels are biomarkers of lupus nephritis and disease activity in Taiwanese. Arthritis Res Ther 2018;20:193.

23. Romporn S, Hirankarn N, Tangkijvanich P, Kimkong I. Association of IFNAR2 and IL10RB genes in chronic hepatitis B virus infection. Tissue Antigens 2013;82:21-25.

24. Gong QM, Kong XF, Yang ZT, et al. Association study of IFNAR2 and IL10RB genes with the susceptibility and interferon response in HBV infection. J Viral Hepat 2009;16:674-680.

25. Ma N, Zhang X, Yang L, et al. Role of functional IFNL4, IFNLR1, IFNA, IFNAR2 polymorphisms in hepatitis B virus-related liver disease in Han Chinese population. J Viral Hepat 2018;25:306313.

26. Nakamura T, Miller D, Ruoslahti E, Border WA. Production of extracellular matrix by glomerular epithelial cells is regulated by transforming growth factor-beta 1. Kidney Int 1992;41:12131221.

27. Coleman DL, Ruef C. Interleukin-6: an autocrine regulator of mesangial cell growth. Kidney Int 1992;41:604-606.

28. Horii Y, Muraguchi A, Iwano M, et al. Involvement of IL-6 in mesangial proliferative glomerulonephritis. J Immunol 1989;143:3949-3955.

29. Bevilacqua MP, Pober JS, Majeau GR, Fiers W, Cotran RS, Gimbrone MA Jr. Recombinant tumor necrosis factor induces procoagulant activity in cultured human vascular endothelium: characterization and comparison with the actions of interleukin 1. Proc Natl Acad Sci U S A 1986;83:4533-4537.

30. Sharma K, Cook A, Smith M, Valancius C, Inscho EW. TGF-beta impairs renal autoregulation via generation of ROS. Am J Physiol Renal Physiol 2005;288:F1069-F1077.

31. Park S, Chang YH, Cho YJ, et al. Cytokine-regulated expression of vascular cell adhesion molecule-1 in human glomerular endothelial cells. Transplant Proc 1998;30:2395-2397.

32. Zager RA, Johnson A. Renal cortical cholesterol accumulation is an integral component of the systemic stress response. Kidney Int 2001;60:2299-2310.

33. Atkins RC. Interleukin-1 in crescentic glomerulonephritis. Kidney Int 1995;48:576-586. 
34. Lejeune D, Dumoutier L, Constantinescu S, Kruijer W, Schuringa JJ, Renauld JC. Interleukin-22 (IL-22) activates the JAK/STAT, ERK, JNK, and p38 MAP kinase pathways in a rat hepatoma cell line: pathways that are shared with and distinct from IL-10. J Biol Chem 2002;277:33676-33682.

35. Zhang J, Zhao T, Xu C, Yu H. Four polymorphisms in the IL-22 gene and the risk of cancer: a meta-analysis. J Evid Based Med 2018;11:101-104.

36. Eun YG, Shin IH, Lee YC, et al. Interleukin 22 polymorphisms and papillary thyroid cancer. J Endocrinol Invest 2013;36:584587. 